\title{
Preservation of physical dimensions in a model of reactive synaptogenesis in the red nucleus
}

\author{
MARK B. BROMBERG and MARTIN S. ARKIN \\ University of Michigan, Department of Neurology, Neuroscience Laboratory Building, 1103 E. Huron Street, \\ Ann Arbor, MI 48109 (U.S.A.)
}

(Accepted May 31st, 1983)

Key words: red nucleus - collateral sprouting — shrinkage

\begin{abstract}
Collateral sprouting of cerebral cortical fibers in the red nucleus following destruction of the interpositus nucleus may be effective in restoring activity of rubral neurons. Shrinkage of the deafferented red nucleus was measured to estimate its effect on recording neural activity and its contribution as a stimulus for sprouting. The results suggest that rubral morphology is preserved during the early time course of collateral sprouting when electrophysiological changes are evident.
\end{abstract}

Recent studies suggest that new synaptic contacts form in the central nervous system in response to injury (reactive synaptogenesis). Synaptogenesis as collateral sprouting of cortical fibers has been described in the red nucleus after partial deafferentation - loss of the cerebellar input from the interpositus nucleus ${ }^{13,18}$. Bromberg and Gilman ${ }^{3}$ investigated whether the changes in synaptic connections could alter the discharge pattern of rubral neurons. They observed an immediate reduction in amplitude of rubral multiunit activity after lesions in the interpositus nucleus and a slow increase over time toward prelesion levels, and suggested that the increased number and more proximal location of cortical fiber connections may be partially responsible for the return of rubral discharge activity. An alternative interpretation is that the red nucleus shrinks when the interpositus fibers are destroyed and an apparent increase in amplitude of multiunit activity is produced as rubral neurons move closer to the fixed recording electrodes. In this study, at the light microscopic level, changes were sought in the red nucleus after deafferentation.

Measurements in the red nucleus were made in adult cats $(2.6-3.6 \mathrm{~kg})$ at intervals after unilateral placement of electrolytic lesions in the interpositus nucleus. Two control animals received no lesions (animals C-A and C-B), two survived 4 days after interpositus lesions (animals $4-A$ and $4-B$ ), two survived 7 days (7-A and 7-B), two 14 days (14-A and
14-B), and one survived 28 days (animal 28-A). At sacrifice the animals were placed in a stereotaxic frame and, following perfusion, the brains were blocked in situ with guided cuts perpendicular to the rostrocaudal axis. Ten micron thick sections were cut from paraffin tissue blocks minimizing deviation from the perpendicular to the neural axis. From 5 to 11 histological sections evenly spaced along the rostrocaudal axis were used for measurements in each animal. Four types of measurements were made on both red nuclei in the tissue cross-sections: (1) the area was determined from $80 \times$ projected images by drawing a circumferential line through the nuclei of neurons staining for Nissl substance and situated along the perimeter of the red nucleus. The area of the red nucleus within the circumferential line was measured by a calibrated dot matrix; (2) counts were made of neurons at $80 \times$ within the defined boundaries of the red nucleus which stained for Nissl substance and had a visible nucleolus. No correction factors $^{6}$ were applied to the cell counts since we were interested in differences in numbers of cells in adjacent red nuclei and not in total numbers of cells in the whole red nucleus; (3) the distance between neurons (cell density) was determined by measuring with a calibrated scale the linear distance (nucleolus to nucleolus) between each neuron and its nearest neighboring neuron in the plane of section at $80 \times$ magnification; and (4) a Cambridge/Imanico Quantimet 720 
image analyzer was used to measure the areas of individual neurons and of their nuclei in selected histological sections along the rubral rostrocaudal axis in a selected number of animals.

For each of the 4 measurements the difference between the deafferented red nucleus and the unaffected red nucleus (or right and left in control animals) on each histological cross-section was calculated. Changes expected with shrinkage are diminution in area, reduced distance between cells (increased cell density), loss of cells, or signs of chromatolysis or transsynaptic alteration (change in size of parikarya or nucleus). The Wilcoxon signed rank test was used to assess the statistical significance of differ- ences between the deafferented and intact red nuclei for area, cell number, and distance between cells. One-sided tests were used because the shrinkage hypothesis implies a change in one direction only. Differences in area of the somas and nuclei of individual neurons were tested for statistical significance by a two sample $t$-test. A two-sided test was used because previous studies 1.2 .14 have described both hypertrophic and atrophic chromatolytic changes in rubral neurons.

Examination of the cerebellar lesion sites revealed that along the rostro-caudal axis, all of the posterior segment of the interpositus nucleus and from $25 \%$ to $80 \%$ of the anterior segment was destroyed ${ }^{7}$. In the

\section{TABLE I}

Relative differences in red nucleus cross-sectional area, number of rubral neurons with visible nucleoli, and linear distance between them for control animals and animals surviving 4, 7,14 and 28 days after receiving unilateral interpositus nucleus lesions

\begin{tabular}{|c|c|c|c|c|c|c|c|c|c|c|}
\hline & \multicolumn{4}{|c|}{ Area of red nucleus } & \multicolumn{3}{|l|}{ Number of neurons } & \multicolumn{3}{|c|}{ Distance between neurons } \\
\hline & $\begin{array}{l}\text { No. } \\
\text { of } \\
\text { sec- } \\
\text { tions }\end{array}$ & $\begin{array}{l}\text { Relative } \\
\text { difference }^{*}\end{array}$ & $\begin{array}{l}\text { Wil- } \\
\text { coxon } \\
\text { test }\end{array}$ & $\begin{array}{l}P \\
\text { value }^{* *}\end{array}$ & $\begin{array}{l}\text { Relative } \\
\text { difference }\end{array}$ & $\begin{array}{l}\text { Wil- } \\
\text { coxon } \\
\text { test }\end{array}$ & $\begin{array}{l}P \\
\text { value }\end{array}$ & $\begin{array}{l}\text { Relative } \\
\text { difference* }\end{array}$ & $\begin{array}{l}\text { Wil- } \\
\text { coxon } \\
\text { test }\end{array}$ & $\begin{array}{l}P \\
\text { value }^{* *}\end{array}$ \\
\hline \multicolumn{11}{|c|}{ Control animals } \\
\hline C-A & 6 & $\begin{array}{lll}0.13, & 0.03,-0.14 \\
0.17, & 0.21, & 0.33\end{array}$ & 10.0 & n.s. & 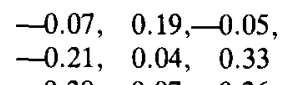 & 9.5 & n.s. & $\begin{array}{lll}0.13, & 0.00, & 0.05 \\
0.26,-0.12, & 0.34\end{array}$ & 17.0 & n.s. \\
\hline C-B & 6 & $\begin{array}{r}0.04,-0.52,-0.11 \\
-0.05,-0.06,-0.06\end{array}$ & 1.0 & 0.03 & $\begin{array}{rr}0.30,-0.07,-0.26 \\
-0.38,-0.09, & 0.62\end{array}$ & 8.0 & n.s. & $\begin{array}{r}-0.11, \quad 0.11,-0.03, \\
0.51,-0.07,-0.44\end{array}$ & 9.0 & n.s. \\
\hline
\end{tabular}

\section{Experimental animals}

$$
\begin{aligned}
& \text { 4-A } 5 \quad 0.08, \quad 0.05, \quad 0.13, \quad 3.0 \text { n.s. } \quad-0.14,-0.26,-0.41, \quad 0.0 \quad 0.03 \\
& \text { 4-B } 7 \quad 0.07,-0.04,-0.10,23.0 \text { n.s. } \\
& 0.08, \quad 0.31, \quad 0.59
\end{aligned}
$$

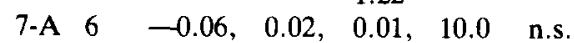

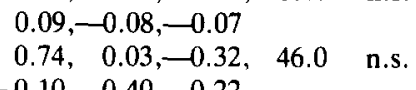

$$
\begin{aligned}
& \text { 7-B } 11 \\
& -0.10,-0.40, \quad 0.22 \text {, } \\
& 0.12,-0.05,-0.17 \text {, } \\
& -0.24,-0.95 \\
& \text { 14-A } 10-0.47,-0.19, \quad 0.12,31.0 \text { n.s. } \\
& -0.02,-0.04, \quad 0.14 \text {, } \\
& 0.32,-0.30, \quad 0.97 \\
& 0.50
\end{aligned}
$$

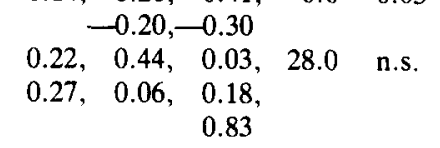

$$
\begin{aligned}
& 0.00, \quad 0.09,-0.32, \quad 12.0 \quad \text { n.s. } \\
& 0.07,-0.49, \quad 0.11 \\
& 0.41,-0.57 .-0.63,28.5 \quad \text { n.s. } \\
& 1.00,-0.14, \quad 0.00 \text {, } \\
& 0.07,-0.48, \quad 0.19 \text {, } \\
& -0.45,-0.67 \\
& -0.25, \quad 0.36, \quad 0.00, \quad 21.5 \quad \text { n.s } \\
& -0.11,-0.20, \quad 0.15 \text {, } \\
& -0.26,-0.20,-0.33 \text {, } \\
& 0.67 \\
& 0.40,-0.20, \quad 0.04, \quad 18.5 \quad \text { n.s. } \\
& -0.44, \quad 0.20, \quad 0.50 \text {, } \\
& -0.37, \quad 1.00 \\
& 0.13, \quad 0.12,-0.26 \\
& 0.03,1.18
\end{aligned}
$$

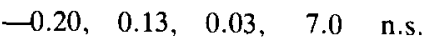

$$
\begin{aligned}
& 0.20,-0.10 \\
& -0.11,-0.02,-0.04,15.0 \text { n.s. } \\
& 0.20, \quad 0.03, \quad 0.44 \\
& -0.05 \\
& 0.13,-0.13, \quad 0.39, \quad 9.0 \quad \text { n.s. } \\
& -0.29, \quad 0.45,-0.32 \\
& -0.07, \quad 0.51, \quad 0.44, \quad 19.0 \quad \text { n.s. } \\
& -0.23,-0.08,0.07 \text {, } \\
& 0.06, \quad 0.29,-0.09 \text {, } \\
& 0.30,2.38 \\
& -0.12,-0.54,-0.28,12.0 \quad \text { n.s. } \\
& 0.01,0.07,-0.16 \text {, } \\
& -0.12, \quad 0.04,0.13 \text {, } \\
& -0.75 \\
& -0.14, \quad 0.12, \quad 0.05, \quad 16.0 \quad \text { n.s. } \\
& 1.05,-0.18,-0.13 \\
& 0.20,-0.73
\end{aligned}
$$

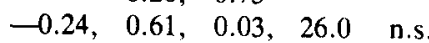

$$
\begin{aligned}
& 0.25,-0.01,-0.47 \text {, } \\
& -0.32, \quad 0.10, \quad 0.83
\end{aligned}
$$

\footnotetext{
* In control animals right red nucleus is compared to left; in lesioned animals, deafferented red nucleus is compared to intact red nucleus.

** $P$ values denote significance of the Wilcoxon signed rank test using one-sided tests. See text for details.
} 
mediolateral dimension, none of the fastigial nucleus was damaged and only small areas of the dentate nucleus were affected. The lesions were similar to those by Bromberg and Gilman ${ }^{3}$ and are considered to interrupt a significant portion of the interpositorubral projection. Comparison of measurements of red nucleus area, cell number, and distance between neighboring cells in the animals with lesions showed no significant differences consistent with shrinkage between the partially deafferented red nuclei and the unaffected opposite nuclei at any time over the 4 week survival period (Table I). One control animal had one red nucleus significantly smaller and one 4 day survival animal had significantly fewer cells $(P<$ 0.05 ). No animal showed a significant increase in cell density. We also considered the data for all cats together to determine if there was a trend across survival times in the magnitude of the differences between the two sides of the nucleus. Regression analyses showed no such relationship for any of the 3 parameters. Although precautions were taken to minimize skewness in cutting the histological sections we tested for its possible effect on the comparisons by shifting the alignment of the various sets of data by one histological section in each direction (a rostrocaudal shift of one red nucleus with respect to the other of about $100 \mu \mathrm{m}$ ); retesting for differences yielded two isolated new significant comparisons.

Since one 4 day animal showed a significant reduction in cell number a further study was made to look for more subtle cellular changes related to chromato- lysis or transsynaptic alterations. Animals from each of the survival periods and one control animal were chosen and individual neurons with visible nucleoli were measured for area of their parikarya and nuclei (Table II). In the control animal there were no significant differences in nuclear area or cytoplasmic area of neurons from both red nuclei. In the experimental group only the 4 day cat showed significant hypertrophy of nuclear and cytoplasmic area of the partially deafferented neurons relative to the normally innervated neurons, while the 7 and 14 day survival animals showed no changes in these measurements. We therefore measured the nuclear and cytoplasmic areas in the other animal which survived 4 days and found no significant changes, and no significant changes when data from both 4 day animals were combined. The 28 day survival animal showed a significant atrophy of nuclear and cytoplasmic area of the affected neurons. The transience of cellular hypertrophy, present at 4 days and absent at 7 and 14 days, is not suggestive of chromatolysis, which may be present 4 days after injury of rubral axons but resolves over a longer time course ${ }^{1}$, or of transsynaptic degenerative changes, which have been shown to require a longer period of onset in the cat ${ }^{4}$. Inspection of the neurons with the light microscope showed no morphological changes consistent with chromatolysis as described for rubral neurons after transection of rubrocerebellar axons ${ }^{2}$ or rubrospinal axons ${ }^{1.14}$.

The results of this study show no statistically significant decrease, or consistent trend, in rubral cross-

\section{TABLE II}

Areas of individual rubral neurons from a control animal and animals surviving unilateral interpositus nucleus lesions for $4,7,14$ and 28 days

In lesioned animals, deafferented rubral neurons compared to intact neurons. Cytoplasm area $=$ total somatic area - nuclear area. $P$ values denote significance of differences between intact and deafferented neurons using paired $t$-tests. See text for details.

\begin{tabular}{|c|c|c|c|c|c|c|c|c|c|c|c|c|c|}
\hline \multirow[t]{3}{*}{ Animal } & \multicolumn{7}{|c|}{ Area of nucleus } & \multicolumn{6}{|c|}{ Area of cytoplasm } \\
\hline & \multicolumn{3}{|c|}{ Intact side } & \multicolumn{4}{|c|}{ Intact side } & \multicolumn{2}{|c|}{ Intact side } & \multicolumn{4}{|c|}{ Intact side } \\
\hline & $n$ & $x$ & $(S . E . M)$. & $n$ & $x$ & (S.E.M.) & $P$ & $n$ & $(S . E . M)$. & $n$ & $x$ & (S.E.M.) & $P$ \\
\hline \multirow[t]{2}{*}{ C-B } & 59 & 209.3 & $(9.9)$ & 60 & 204.6 & $(10.1)$ & 0.74 & 59 & $764.2(58.2)$ & 60 & 738.6 & $(75.2)$ & 0.79 \\
\hline & \multicolumn{3}{|c|}{ Deafferented side } & \multicolumn{4}{|c|}{ Intact side } & \multicolumn{2}{|c|}{ Deafferented side } & \multicolumn{4}{|c|}{ Intact side } \\
\hline $4-A$ & 45 & 265.6 & (15.3) & 64 & 224.8 & $(10.6)$ & 0.03 & 45 & $1217.6(96.4)$ & 64 & 889.9 & $(67.7)$ & 0.005 \\
\hline 4-B & 105 & 194.2 & $(8.1)$ & 93 & 201.8 & $(8.5)$ & 0.52 & 105 & $841.3(48.5)$ & 93 & 825.8 & $(56.9)$ & 0.84 \\
\hline 7-B & 119 & 309.4 & (11.6) & 110 & 324.5 & $(11.4)$ & 0.35 & 119 & $1516.9(90.3)$ & 110 & 1320.0 & $(86.9)$ & 0.12 \\
\hline $14-B$ & 70 & 218.1 & (11.2) & 69 & 212.0 & (12.1) & 0.71 & 70 & $814.4(60.0)$ & 69 & 893.1 & $(84.0)$ & 0.44 \\
\hline $28-\mathrm{A}$ & 60 & 197.2 & (11.3) & 40 & 242.2 & $(14.5)$ & 0.01 & 60 & $836.9(74.3)$ & 40 & 1083.1 & $(104.4)$ & 0.05 \\
\hline
\end{tabular}


sectional area, cell number, or cell density after partial deafferentation of the red nucleus. Our initial measurements indicated significant changes in the size of individual neurons in animals at 4 and 28 days survival. The importance of significant differences in the one 4 day animal was diminished when the second 4 day animal was examined and no significant differences were found. We conclude that during the first few weeks, when reactive synaptogenesis occurs ${ }^{18}$, no morphometric changes can be detected with a light microscope in rubral neurons after destructive lesions in the interpositus nucleus. At later times cellular atrophy may commence.

There are two possible reasons for failure to find significant morphometric changes: either there were, in fact, no changes, or the experimental procedures were not sufficiently sensitive to detect them. Changes in the area of the red nucleus in the coronal plane were considered appropriate because of the caudo-rostral projection of interpositus cell axons. Comparisons were made between a partially deafferented red nucleus and an opposite, unaffected mate, and skewness of the planes of section could confound side-to-side comparisons. These is no unequivocal procedure or test to ensure homology of neighboring nuclei, and nuclei may not be bilaterally identical. An attempt at primary measurement of skewness by making marker lesions in the mesencephalon was found to be insensitive. Shifting the alignment of the various sets of data produced a new significant comparison in two isolated sections and we discount skewness as an error factor. We chose to study cells staining for Nissl substance which are the large and medium sized rubral neurons described in several species $^{9,10,16}$. A third rubral cell type, small neurons without Nissl substance, was excluded because they are difficult to distinguish from perirubral neurons ${ }^{11}$. The neurons used for determination of cell number and cytoplasmic and nuclear area were identified by the presence of visible nucleoli and underestimates of their number occurred because the diameter of the nucleoli is small compared to the distances between the sections (greater than $100 \mu \mathrm{m}$ ).

1 Barron, K. D., Dentinger, M. P., Nelson, L. R. and Schiebly, M. E., Incorporation of tritiated leucine by axotomized rubral neurons, Brain Research, 116 (1976) 251-266.
The failure to observe chromatolytic changes in rubral neurons following lesions in the interpositus nucleus may be due to the use of adult animals. Brodal and Gogstad $^{2}$ found chromatolytic changes to be most apparent in newborn cats. Sadun and Pappas ${ }^{16}$ described in cats substantial changes in dendritic and axonal morphology during the first 6 weeks of life which may make older cats more resistant to chromatolytic changes. Less is known about transsynaptic alterations but there is evidence of changes occurring in the cat over longer time periods than examined here ${ }^{4}$.

A lack of shrinkage in the red nucleus is not unexpected for, although some studies carried out in other parts of the brain on the effects of partial deafferentation demonstrate evidence of shrinkage ${ }^{12,15}$, others do not ${ }^{8}$ and it appears that shrinkage is related to the volume of fibers undergoing degeneration. The stimuli which initiate reactive synaptogenesis in this model remain unknown. Since shrinkage is not a significant factor, vacant postsynaptic sites may provide a signal eliciting new growth from intact nearby fibers $^{5}$. Of interest, however, is the recent demonstration that similar reorganization of corticorubral synapses to more proximal sites on rubrospinal neurons follows cross-union of flexor and extensor nerves in the forelimb of otherwise intact cats ${ }^{17,19}$. These experiments suggest a mechanism of synaptogenesis not requiring widowed sites on the postsynaptic membrane. Since we observed no postsynaptic changes at the light microscopic level, and none were found by Nakamura et al. ${ }^{13}$ using an electron microscope, other mechanisms need to be postulated which are related to altered patterns of neural input to rubrospinal neurons from the cerebral cortex and cerebellar nuclei. A common mechanism may be operative in both the partial deafferentation model and the nerve cross-union model, where deafferentation represents an extreme change in neural input.

Supported in part by United Cerebral Palsy Educational and Research Foundation, Inc. Grant R310-78.

2 Brodal, A. and Gogstad, A. C., Rubro-cerebellar connections. An experimental study in the cat, Anat. Rec., 118 (1954) 455-485.

3 Bromberg, M. B. and Gilman, S., Changes in rubral mul- 
tiunit activity after lesions in the interpositus nucleus of the cat, Brain Research, 152 (1978) 353-357.

4 Cook, W. H. Walker, J. H. and Barr, M. C., A cytological study of transneuronal atrophy in the cat and rabbit. $J$. comp. Neurol., 94 (1951) 267-292.

5 Cotman, C. W. and Nadler, J. V., Reactive synaptogenesis in the hippocampus. In C. W. Cotman (Ed.). Neuronal Plasticity, Raven Press, New York, 1978, pp. 227-272.

6 Ebbesson. S. O. E. and Tang. D.. A method for estimating the number of cells in histological sections, J. roy. Micros. Soc., 84 (1965) 449-464.

7 Flood. S. and Jansen, J., On the cerebellar nuclej in the cat, Acta anat., 46 (1961) 52-72

8 Goodman. D. C. and Horel, J. A., Sprouting of optic tract projections in the brain stem of the rat. J. comp. Neurol.. $127(1966) 71-88$.

9 King. J. S., Schwyn, R. C. and Fox, C. A., The red nucleus in the monkey (Macaca mulatta): a Golgi and an electron microscopic study. J. comp. Neurol., 142 (1971) 75-108.

10 King, J. S., Bowman, M. H. and Martin, G. F., The red nucleus of the opossum (Didelphis marsupialis virginiana): a light and electron microscopic study, J. comp. Neurol., 143 (1971) 157-184

11 King. J. S. Dom. R. M. and Martin, G. F., Anatomical evidence for an intrinsic neuron in the red nucleus. Brain Research, 67 (1974) 317-323.

12 Lynch, G. and Cotman, C. W.. The hippocampus as a model for studying anatomical plasticity in the adult brain. In R.
L. Isaacson and K. H. Pribram (Eds.), The Hippocampus, Plenum Press, New York. 1975, pp. 123-154.

13 Nakamura, Y., Mizuno, N., Konishi, A. and Sato, M., Synaptic reorganization of the red nucleus after chronic deafferentation from cerebellorubral fibers: an electron microscope study in the cat, Brain Research, 82 (1974) 298-301.

14 Prendergast, J. and Stelzner, D. J., Changes in the magnocellular portion of the red nucleus following thoracic hemisection in the neonatal and adult rat, J. comp. Neurol., 166 (1976) 163-172.

15 Raisman, G. and Field, P. M., A quantitative investigation of the development of collateral reinnervation of the septal nuclei, Brain Research, 50 (1973) 241-264.

16 Sadun, A. A. and Pappas, G. D., Development of distinct cell types in the feline red nucleus: a Golgi-Cox and electron microscopic study. J. comp. Neurol., 182 (1978) 315-366

17 Tsukahara, N, and Fujito, Y., Physiological evidence of formation of new synapses from cerebrum in the red nucleus neurons following cross-union of forelimb nerves, Brain Research, 106 (1976) 184-188.

18 Tsukahara, N., Hultborn, H., Murakami, F. and Fujito, $Y$., Electrophysiological study of formation of new synapses and collateral sprouting in red nucleus after partial denervation, J. Neurophysiol., 38 (1975) 1359-1372.

19 Tsukahara, N., Synaptic plasticity in the red nucleus. In C. W. Cotman (Ed.), Neuronal Plasticity, Raven Press, New York. 1978, pp. 113-130. 